\title{
O transhumanismo e a questão antropológica
}

\author{
Transhumanism and the anthropological question
}

WENDELL E. SOARES LOPES ${ }^{a}$

\section{Resumo}

Quando nos detemos à querela recente sobre o enhancement, especialmente àquela que tem colocado em lados opostos bioconservadores e transhumanistas, não pode passar despercebido que pressuposições e mesmo concepções muito ingênuas sobre o homem se encontram no fundo do debate. No estudo que apresentaremos, buscaremos mostrar duas teses: antes de tudo, tentaremos evidenciar que tal querela formada em torno do enhancement é uma reformulação da querela que outrora envolveu a arte alquímica nos tempos medievais e renascentistas - arte cujo impulso deu grande influxo ao ideal práticotransformador da ciência. Em segundo lugar, mostraremos que a atual controvérsia em torno do transhumanismo padece, em termos ontológicos, de problemas semelhantes àqueles que atormentavam o debate sobre aquela antiga arte. Por fim, deixaremos, entretanto, indicado que o esclarecimento das questões ontológicas envolvidas em tal controvérsia não eliminam necessariamente outras questões de ordem ética e política, as quais precisam certamente de um estudo complementar.

Palavras-chave: Transhumanismo. Transhumanistas. Bioconservadores. Natureza humana.

\section{Abstract}

When we look at the recent quarrel about enhancement, especially the one that has been put on opposite sides bioconservatives and transhumanists, it cannot be

aUniversidade Federal de Mato Grosso (UFMT), Cuiabá, MT, Brasil. Doutor em Filosofia, e-mail:wendellsoareslopes@gmail.com 
overlooked that very naive assumptions and conceptions about man lie at the bottom of the debate. In the present study, we will try to show two theses: first of all, we will try to show that such a quarrel about enhancement is a reformulation of the quarrel that once involved alchemical art in medieval and Renaissance times - art whose impulse gave great influence to the practical and transformer ideals of science. Secondly, we will show that the current controversy over transhumanism suffers, ontologically, from problems like those that plagued the debate about that ancient art. Finally, we will point out, however, that clarifying the ontological issues involved in such controversy does not necessarily eliminate other ethical and political issues, which certainly need further study.

Keywords: Transhumanism. Transhumanists. Bioconservatives. Human nature.

\section{Introdução}

A vontade de potência que comanda a necessidade de manipulação e transformação da essência humana sempre atuou nos desígnios dos homens desde a mais tenra aurora da ciência moderna, tão devedora da tradição mágica e alquímica. Duas grandes figuras dominaram essas intenções transformativas: o golem e o homúnculo, nas suas mais distintas versões. O impulso alquímico da ciência moderna em sua expressão contemporânea através das novas tecnologias visa agora à transmutação alquímica dos seres humanos mais do que nunca. O problema que pretendo tratar neste ensaio parte exatamente do desenvolvimento da atual cibernética e da biologia molecular ou, se se preferir, para fazer frente a física nuclear, poderíamos tratar como a biologia nuclear, ambas responsáveis por levantarem questões éticas as mais diversas, criando a partir daí um debate imenso que em muitos aspectos tem sucumbido a controvérsias pouco frutíferas, colocando de lados opostos bioconservadores e transhumanistas. Tendo em vista esta situação, o que buscarei no presente ensaio é apenas limpar o terreno ontológico que está na base de boa parte desse controverso debate sobre o melhoramento (enhancement) humano. De maneira mais específica, o trabalho aborda o difícil problema levantado 
pelas técnicas de melhoramento humano para a questão antropológica. Há, de fato, algo como o transhumano ${ }^{1}$ ou as diversas formas de enhancement que possivelmente esperam-nos no futuro não colocam em questão a essência humana? $\mathrm{O}$ que marca a diferença antropológica? E em que sentido os transhumanistas pensam a essência humana aqui? Tendo-se em vista os efeitos da atual antropotécnica, faz, de fato, sentido falar de uma alteração da essência humana?

Essas são algumas das questões que abordarei. Defenderei a tese de que apesar da constante afirmação de transhumanistas que um ultrapassamento do humano nos espera em futuro não muito distante, as perspectivas que usualmente se imagina como modelos do transhumano parecem pressupor uma concepção muito frágil sobre a natureza humana, errando, pois, na avaliação do que seria o transhumano e sua emergência. Mas antes de passar propriamente à questão central que desejo tratar, oferecerei uma breve exposição sobre a produção artificial do homem na tradição alquímica, uma vez que penso que ela nos oferece uma primeira visão das alternativas oferecidas pelas atuais antropotécnicas.

\section{Sobre a alquimia: da transmutação dos metais à criação artificial do homem}

Um esboço histórico do problema da alquimia no final do medievo, especialmente no século XIII, a respeito da possibilidade da criação artificial de novas formas de metais, pode ser traçado a partir de duas claras oposições que os

\footnotetext{
${ }^{1}$ Há quem tome os termos pós-humanismo e transhumanismo como significando movimentos semelhantes, mas aqui tomo os dois termos como distintos. Conservo o termo pós-humanismo para o movimento filosófico que critica o humanismo desde uma perspectiva que nega a própria ideia de natureza humana, como é o caso com pensadores como Foucault, Derrida e até mesmo Agamben. Pode-se ainda falar em hiper-humanismo, que, claro, possui uma significação diferente das duas anteriores, já que meramente defende uma intensificação das propriedades humanas.
} 
alquimistas receberam: a primeira vindo de filósofos e teólogos aristotélicos embora tenham existido exceções — , e a outra, especialmente a partir da renascença em diante, da parte especificamente de artistas. A querela se encontrava basicamente em torno da distinção entre o natural e o artificial. Aqui, entretanto, interessa-nos apenas o problema envolvendo a contraposição entre os alquimistas e seus oponentes filosóficos e teológicos.

A história da ciência em sua relação com a alquimia parte da tomada de posição em relação à famosa afirmação de Aristóteles na Física (II 8, 199a 15-17), que diz o seguinte: "em alguns casos a arte aperfeiçoa aquilo que a natureza não pode completar, em outros imita a natureza". De um lado, os oponentes acreditam que a alquimia é arte operativa e de forma mais clara arte mecânica, isto é, adulteradora, e, portanto, incapaz de realizar genuína transmutação da forma substancial, enquanto os alquimistas defendem sua nobreza como uma ciência oculta capaz de transformar a natureza, indo além dela e trazendo-lhe aperfeiçoamentos. E não se pode deixar de dizer que a querela é alimentada por concepções distintas sobre o que é uma "espécie", como se evidencia na relação entre as posições de Avicena e Hermes, por exemplo.

Naturalmente, a alquimia resiste ao ataque e essa querela se prolonga pela renascença, chegando a influir sobre os mais importantes nomes para o estabelecimento da ciência moderna como, por exemplo, Francis Bacon, Kepler e Newton. Não é minha intenção, aqui, seguir essa história. Antes, direciono agora a discussão para um outro âmbito em que ela aparece, em que o uso da alquimia ganha ares realmente fantásticos: refiro-me, claro, à passagem da transmutação dos metais para o objetivo muito mais ousado da produção artificial do ser humano. E aqui destacarei apenas algumas importantes versões das duas mais importantes figuras que a tradição mágica e alquímica nos legou sobre esse tema, a saber: o golem e o homúnculo, que embora para as cabeças modernas não tenham senão a aparência de especulações exóticas, não eram desautorizadas pela "biologia" da época, ainda dominada pela aceitação da teoria da geração espontânea e do papel 
especial do sêmen na geração humana, e também pelo mito cosmogônico do Deus criador (este último sendo base da própria ideia do Golem medieval)².

Passo então, primeiro, à figura do golem, que é fundamentalmente de origem judaica, e possui três versões mais famosas, das quais explicitarei muito brevemente apenas uma. Nela, tendo sua origem na cabala, o golem é um homem artificial trazido à vida a partir de magia religiosa - especialmente a partir do poder da palavra divina. De maneira mais específica, tais criaturas eram feitas com a figura de um homem na argila e pelo poder da palavra a escultura de argila ganhava vida. Para tirar-lhe a vida bastava tirar o primeiro "e" do nome emeth (verdade) inscrito em sua testa, ficando assim o termo meth, que quer dizer "morto". Reza a lenda que Rabbi Elias dera forma a um golem tão grande que não conseguia mais alcançar-lhe a testa. Ele armou um jeito de apagar o "e", mas ao conseguir fazê-lo a matéria do golem despencou sobre ele, o matando.

As imagens sobre a criação do homúnculo são bem mais numerosas, e vêm de duas tradições principalmente (arábico-islâmica e latina) e em boa parte reclamam poderes especiais a seu rebento artificial. A primeira vez que a imagem de um verdadeiro homúnculo gerado por ectogênese aparece na literatura se encontra na história de Salaman e Absal, que data da mesma época do texto de Zosimos. A narrativa fala de um rei, Harmanus, que sem filhos e repugnando a ideia de manter relações sexuais com uma mulher, sofria por sua situação de não ter um descendente. O asceta Qaliqulas, conhecedor das ciências ocultas, lhe sugere então ter um filho homem por meios artificiais. Bastava apenas pegar o sêmen do rei, colocar num frasco, e utilizar uma técnica especial que Qaliqulas dominava. O rei concordou e depois do procedimento nasceu Salaman. Aí estão pressupostas as duas teorias aristotélicas da geração espontânea e do papel especial do sêmen na geração, só que com um acréscimo importante: é o esperma como tal que permite a geração espontânea de uma nova vida humana.

\footnotetext{
${ }^{2}$ Uma análise mais detida da discussão que apenas esboço a seguir pode ser encontrada em Promethean Ambitions, de William Newman (2004).
} 
Diferente dessa situação, se destaca uma das tradições árabe-islâmicas, que se encontra representada no Livro da Vaca (Liber vaccae). Aí o esperma humano (que aparece explicitado com o termo "água") é combinado com um material fluorescente que o autor, pseudo-Platão, chama de pedra de sol, podendo assim gerar um "animal racional", se alojado numa matriz apropriada, que poderia ser tanto uma vaca ou uma ovelha preparada de maneira muito peculiar. O produto aqui (o homúnculo "encarnado" pelo animal racional) é, entretanto, diferente do tipo de ser que Salaman representa enquanto um ser humano de carne e sangue. $\mathrm{Na}$ medida em que combinado à pedra de sol, o animal racional é literalmente um ser de luz, e disso há que se entender: seus poderes excedem aqueles dos pobres e terrenos mortais. Esse animal racional era algo que não um humano.

\section{O transhumanismo e a questão antropológica}

O poder científico técnico se elevou de forma tão estrondosa que o que era mera especulação fantástica pairando no ar — a criação artificial do humano — passa hoje, entretanto, a querer pisar o chão da realidade. Com os feitos que vão das variadas formas de técnicas de reprodução assistida (IVF, ICSI, etc.), passando pelas também variadas técnicas de eugenia negativa e positiva, pela clonagem (terapêutica e reprodutiva), até chegar às realidades e promessas da manipulação genética e da cibernética pensada em toda a convergência de áreas que vão da robótica, a nanotecnologia e as ciências cognitivas), não sem boa dose de fanatismo e fantasia ouve-se por todos os lados falar da transmutação do humano e da chegada do transhumano.

É nesse clima de entusiasmo que corre solta, já faz tempo, a querela sobre o enhancement, que separa e esquenta os ânimos de bioconservadores e transhumanistas. A querela foi bem resumida por Savulescu e Bostrom (2009, p. 1) do seguinte modo: 
os transhumanistas, por um lado, [são] aqueles que acreditam que uma ampla extensão de melhoramentos deveriam ser desenvolvidos e que as pessoas deveriam estar livres para utilizá-los para transformarem-se de formas bastante radicais; e bioconservadores, por outro, [são] aqueles que acreditam que não deveríamos alterar substancialmente a biologia humana ou a condição humana.

Deixando de lado a divisão binária que não atende ao espectro de posições muito nuançadas, com expressões como “deveriam”, "não deveríamos”, "de formas bastante radicais" e "alterar substancialmente", esse resumo destaca claramente tanto o elemento ético como ontológico envolvido na querela. Como deixei indicado desde o início, não tratarei das questões éticas e políticas. Antes interessame aqui os aspectos ontológicos do problema. E de saída há que se dizer que quando se analisa de perto o debate sobre o enhancement é impossível não perceber que, em seu fundo, pressuposições e mesmo concepções muito ingênuas sobre o homem se encontram determinando o debate, às vezes mascaradas, às vezes fornecendo o próprio material de controvérsia - que em boa medida sofre de problemas semelhantes aos que apareceram na controvérsia em torno do poder transmutador da alquimia. Como segundo passo do presente trabalho, então, quero analisar justamente esses aspectos ontológicos pressupostos a passos contados.

Quando se lê alguns textos de bioconservadores e transhumanistas, a resposta - e muitas vezes a pressuposição envolvida — para a natureza humana parece ser a de que melhoramento é a interferência técnica ou artificial que como resultado permite realizar atividades num nível — quantitativamente pensado maior à média ou a todos os homens até hoje. Nesse sentido, seria transhumano viver 200 anos, por exemplo, ou caso possua uma inteligência acima do que os humanos até hoje exibiram - e inteligência é aqui tratada, às vezes, a partir da ideia de coeficiente de inteligência (QI) (cf. SAVULESCU, 2001, p. 414). O humano é, portanto, tratado desde uma medida de desempenho, uma expressão do rendimento, de certas capacidades corporais e mentais. O "trans" aparece aí como uma mera representação quantitativa. Mas para além dessa primeira formulação muito simplista, vale a pena atentar para uma reflexão mais sofisticada do problema. 
Peter Sloterdijk elabora o problema da criação do homem e o problema da antropotécnica a partir de uma verdadeira "antropologia histórica” (SLOTERDIJK, 2008, p. 108) ou "paleoantropologia" (SLOTERDIJK, 2011, p. 191) que busca mostrar que a humanização constituiu a "história natural do antinatural no homem" (2011, p. 191; 2008, p. 109), que para além da ideia de uma unidade original e integral entre homem e natureza - gesto nostálgico-romântico e mentalidade holística-ecopietista a um só tempo — se revela antes como história da libertação progressiva do homem em relação ao seu ambiente (cf. SLOTERDIJK, 2008, p. 108). Ao criticar a ficção do ser de falta (Mangelwesen), tão própria de Arnold Gehlen, Sloterdijk contrapõe ao bomo compensator o seu bomo luxus, isto é, o homem enquanto "ser distanciado que, em virtude de uma evolução especial de suas técnicas de distanciamento, pôde moldar-se como um membro de luxo das comunidades naturais de seres vivos" (SLOTERDIJK, 2011, p. 191). É a essas "técnicas de distanciamento" que moldam o homem como ser de luxo que Sloterdijk dá o nome de antropotécnica. Estas antropotécnicas são "os procedimentos de exercitação, físicos e mentais, com que os homens das culturas mais díspares tentaram otimizar seu estado imunológico frente aos vagos riscos da vida e às agudas certezas da morte" (SLOTERDIJK, 2012, p. 24). E na história dessa humanização, do mesmo modo que os jogos olímpicos foram já uma forma de desespiritualização da ascese religiosa, as novas formas antropotécnicas encabeçadas pelas biotecnologias seriam uma nova forma de desespiritualização ascética.

Até aqui a reflexão de Sloterdijk não vai além do humano. Isso não significa, entretanto, que ele não vislumbre uma opção transhumana. Não obstante, para ele, esta nova alternativa corre não na trilha da bioengenharia, mas da cibernética. $\mathrm{O}$ filósofo distingue três níveis da engenharia humana, distinção essa que traz para a discussão uma releitura e tradução do antigo problema alquímico para a esfera da contemporânea antropotécnica que era o ponto de partida desse estudo. Além do engenheiro primário, o engenheiro secundário aparece no impulso do homem em buscar alcançar o outro lado da Criação, deixando assim de ocupar o papel de mero criado, para conquistar o status de criador. Para Sloterdijk há claramente "uma 
continuidade de concepções" desde os "antigos metalúrgicos até os alquimistas medievais e protomodernos" (SLOTERDIJK, 2011, p. 193). Mas uma diferença mais deve ser estabelecida: além do engenheiro secundário, que é um acelerador da gravidez de metais, manipulador do ritmo da natureza, isto é, do tempo da maturação, como é o caso com as biotecnólogos atuais, Sloterdijk, seguindo neste ponto a Gotthard Günther (1963), sugere que deve-se falar ainda de um engenheiro terciário, com o qual se explicita a diferença entre homúnculo e robô (mechanical brain). Sloterdijk resume este novo passo assim: "enquanto os alquimistas só pretendiam acelerar mediante um arranjo das forças eficazes latentes na natura naturans", diz, "os engenheiros construtores [terciários] de robô compõem todo o sistema de ação cibernética com elementos constituídos ao efeito" (SLOTERDIJK, 2011, p. 194n11). É só com esse terceiro nível de engenharia que Sloterdijk se permite falar de uma cotitularidade na criação da natureza e a possível "humilhação [do homem] pelas máquinas” (cf. SLOTERDIJK, 2011, p. 221-240).

Ora, essa estrutura de Solterdijk acerca de três formas de engenharia que passam pelas antropotécnicas de criação/seleção (Züchtung) e de manipulação genética e aquelas levadas a cabo pela cibernética têm a vantagem de derrubar a visão sofística do transhumanismo que se esforça simplesmente por equivaler terapia e enhancement. Mas o fato é que ainda assim é possível pensar pelo menos o DNA recombinante como também devendo ser discutido quando a questão é a possibilidade do transhumano, e ainda mais do que a possibilidade cibernética. De qualquer modo, parece valer para a nossa análise a sugestão de William Newman a respeito da relação entre os intentos da alquimia e das atuais antropotécnicas, qual seja:

o golem pertence ao domínio da vida artificial 'forte', o mundo da robótica, cibernética, e inteligência artificial, onde os processos biológicos comuns são enfrentados ou simulados por meios não biológicos. O homúnculo propriamente é o rebento do mundo 'molhado' da fertilização in vitro, da clonagem, e da engenharia genética, onde a biologia não é falsificada, mas alterada" (NEWMAN, 2004, p. 187).

Mas até que ponto o golem moderno, enquanto modelo do transhumano cibernético, e o homúnculo moderno, enquanto modelo do transhumano ainda 
bioprojetado, oferecem de fato um caminho para o transhumano? Esta pergunta exige que se elabore a análise das duas direções fundamentais em que o aparecimento do transhumano supostamente acena. Vejamos então cada uma das duas possibilidades, aquela da cibernética e seu golem 2.0, bem como o novo homúnculo da biotecnologia.

Para a reflexão sobre a via da cibernética, o nome de Raymond Kurzweil é atualmente passagem obrigatória. Ele é um inventor futurista dos mais renomados e tem escrito sobre o futuro da cibernética. O número de invenções que contam com sua assinatura impressiona: entre elas estão os sintetizadores Kurzweil, primeiro a ser capaz de reproduzir um piano, e outras hightechs como o primeiro reconhecedor óptico de caracteres, a primeira máquina de leitura para cegos, primeiro sintetizador de texto-para-voz comercial, etc. Com essas credenciais Kurzweil passou a representar uma das grandes vozes do movimento transhumanista e em seu livro The Singularity is Near (2005) prevê que os avanços tecnológicos aumentarão em uma escala exponencial. Segundo o que ele chama de "lei dos retornos acelerantes". Como sumário do espectro de tecnologias atendidas por esta lei, ele identifica a genética, a nanotecnologia e a robótica (GNRtechs - tecnologias GNR). Com essa revolução exponencial das GNRtechs, a humanidade conhecerá o que Kurzweil chama de "singularidade": "um período futuro durante o qual o ritmo de mudança tecnológica será tão rápido e seu impacto tão profundo que a vida humana será transformada irreversivelmente" (KURZWEIL, 2005, p. 7). 2045 é a previsão do autor para a singularidade, tempo em que assistiremos a uma mente artificial um trilhão de vezes mais inteligente que a humana. Mas além de robôs de inteligência ultra-humana, Kurzweil prevê também, tal como implantes para audição, um "hipocampo protético" que poderá ter capacidade mental, tornando-se assim uma opção de mind uploading; já em 2029 as trajetórias neurais seriam aperfeiçoadas por conexão bigh-banwidth com o cérebro humano, para melhorar a percepção, memória e raciocínio. Enfim, a lista é enorme.

Nas breves considerações sobre porque não vejo um futuro transhumano desse lado da busca de criação cibernética, quero ater-me apenas a uma das muitas 
predições de Kurzweil, aquela que considero a mais ousada e também mais problemática: a própria ideia de uma inteligência artificial ultra-humana. A razão para tal é antes de tudo a desventura técnica das outras alternativas. Por um lado, Stock observa, por exemplo, que a tentativa de melhorar os humanos com a inserção de chips em nosso cérebro é improvável e não trará melhoras, pois a interface entre cérebro e sílica é inevitavelmente complexa (cf. STOCK, 2002, p. 20). Em especial, Stock rebate a possibilidade da conexão high-banwidth com o cérebro humano (cf. STOCK, 2002, p. 21-22). Que um implante cibernético possa aumentar o raciocínio (ou inteligência) é ainda mais duvidoso. Quanto à ciborguização, mais uma vez penso que Stock acerta ao dizer que ela tem o irrealismo contra si: "Os ganhos são muito pequenos, os desafios, enormes, os riscos, muito grandes, e as alternativas, muito numerosas" (STOCK, 2002, p. 27). Casos como o de Kevin Warwick, que implantou um chip rastreador (conectado ao computador) que permite que certas operações feitas pelo PC aconteçam (p. ex.: a abertura da porta de sua casa) são, como afirma Stock, muito mais teatral do que a realidade dos implantes, os quais terão muito mais o caráter de reparos corporais do que qualquer outra coisa. O único lugar onde o "compromisso com nosso corpo" não é a melhor opção é a situação de combate, onde certamente robôs serão destruídos sacrificialmente no lugar de humanos. Não sem motivos, Stock vê mais futuro para os fiborgues (termo cunhado pelo pesquisador em Inteligência Artificial Alexander Chislenko), antes que para os ciborgues. A diferença é a seguinte: "a ciborguização incorpora componentes maquínicos em nossos corpos. A fiborguização nos funde funcionalmente, antes que fisicamente, com máquinas" (STOCK, 2002, p. 25). Basicamente, o fiborgue é o ciborgue funcional. Assim, as "predições da fusão iminente entre humano e máquina ignoram o grau com que somos biológicos em nossa natureza e queremos continuar desse modo" (STOCK, 2002, p. 29). Como resultado, a tese é a seguinte: a crescente fiborguização inibirá a ciborguização, relegando-a ao mero reparo funcional. Por uma "lógica" muito parecida a de Stock, Andrew Feenberg também não dá importância às expectativas dos que esperam o dia de terem seus cérebros descarregados (dowloaded) em 
computadores, como aqueles que sonham um dia compor um borganismo. Diz ele: "não vejo o que isso possa significar para aqueles dentre nós que utiliza a internet diariamente e ainda permanecem firmemente compromissados com a existência corporal' (FEENBERG, 2012, p. 6, grifo meu). Para estender essa linha de raciocínio de Feenberg, permito-me uma ironia filosófica: num mundo onde as religiões fizeram um esforço descomunal para, através de exercícios ascéticos, livrar os humanos de sua existência de carne e sangue, visando torná-los assim quase-angelicais - e fracassando, diga-se em alto e bom tom! — não creio que seria agora a promessa de uma existência informacional descarregada nas redes computacionais que seduzirão os humanos a largarem sua vida carnal para aceder, enfim, a uma vida puramente “espiritualizada". Tal como a religião gnóstica, o novo "ascetismo" tecnológico não terá vida longa entre os carnais humanos. Além disso, apesar de uma belíssima solução ecológica para o mundo atual, a existência borg tem ainda contra si o dramático problema da perda de identidade pessoal, que, embora muitos adeptos transhumanistas já estejam dispostos a aceitar, não será o caso com os nossos egoístas humanos. Enfim, é preciso, em outras palavras, se considerar o fator apropriativo e assimilativo que se encontra do lado dos usuários das tecnologias algo que bem enfatizaram Gregory Stock e Andrew Feenberg. Do ponto de vista propriamente ontológico, há que se dizer criticamente que a ciborguização - e muito menos a fiborguização — só esfumaça a linha entre máquina e humano quando se possui uma concepção substancial e morfológica - muito ingênua por sinal — de natureza humana. Por isso, a única diretriz ontológica realmente digna de consideração se encontra na ideia de inteligência artificial em sentido forte.

A esse respeito, o "ciberneticista" Kurzweil, como salientei, espera a chegada dessas inteligências já para 2029. Há que se dizer que por inteligência artificial o que ele entende é uma máquina capaz de passar ao teste de Turing, isto é, uma máquina que consiga enganar um ser humano em 30-50\% de suas respostas. Mas isso, devemos perguntar, representa, de fato, a conquista de uma inteligência humanomáquina que acena para uma inteligência ultra-humana no futuro? Se esse é o parâmetro, não posso senão seguir serenamente os transhumanistas nessa 
afirmação. Tratou-se de uma das mais ingênuas atitudes considerar que uma máquina enxadrista, por exemplo, não pudesse vencer um humano em uma partida de xadrez. O erro de avaliação estava em não ter-se prestado atenção ao fato de um jogo de xadrez ter em essência a mesma estrutura de um cálculo. E a esse respeito, é claro que as calculadoras são mais rápidas e eficientes que a esmagadora maioria dos cérebros humanos. Não há, portanto, que se duvidar que os robôs venham a realizar tarefas "calculatórias" com muito mais aptidão. Mas confundir essa capacidade com o que propriamente faz o humano é apenas a expressão de uma diretriz ontológica que encontra na ideia de inteligência artificial em sentido forte a única orientação realmente digna de consideração. Pois, parece-me claro que, em termos ontológicos, não se pode, de fato, falar de máquinas inteligentes, no sentido humano de inteligência. Ao que parece, também aqui a expectativa parece não ater-se à diferença nítida existente entre o mero cálculo e o pensamento humano, em que se exige intencionalidade, sentimento, semântica, etc. (cf. SEARLE, 1990; JONAS, 1993, p. 49-51).

Naturalmente, aqui a consciência é o elemento mais poderoso de separação, mas se se quer apresentar o problema em outros termos, pode-se dizer que o robô cibernético, representa apenas uma nova imagem do Golem judaico: como este último, ele é matéria informada, mas jamais matéria informante. Num nível propriamente humano, isso quer dizer que tal como o antigo Golem da narrativa do Talmud esse novo Golem não possui a fala humana; falta-lhe a linguagem humana, e, portanto, a capacidade de significar, ou se se preferir, a capacidade de dar sentido, de formar novos padrões de informatização.

Poder-se-ia objetar a esse argumento com a ideia de que com a singularidade, as máquinas não apenas vão agir segundo uma programação, mas serão elas também capazes de programar. Elas seriam até mesmo programadores mais potentes e perfeitos que os humanos. Tais programadores robóticos ou computacionais produziriam outros programadores cada vez mais complexos até que os humanos não pudessem mais compreender o que está em jogo, estando expostos assim a uma ditadura maquínico-computacional organizada por um algoritmo complexo 
incompreensível e mesmo inacessível ao ser humano. Deixarei de lado as preocupações de alguns com cenários sombrios, porque me parece desnecessário ceder a tais preocupações. Atenho-me antes à ideia de programas programadores com potenciais de programação superiores aos dos humanos. Estaríamos aqui então diante do transhumano?

A resposta a essa questão depende do que dissera eu anteriormente na comparação entre máquina enxadrista, calculadoras e humanos: não se pode afirmar que uma máquina é transhumana porque calcula mais rápida e precisamente que um humano, do mesmo modo que Kasparov não é transhumano por ser capaz de me vencer cem por cento das vezes que viéssemos a nos enfrentar num jogo de xadrez. E a explicação para isso é simples: a mesma inteligência, governada pelas mesmas leis lógicas está em jogo na calculadora, na máquina enxadrista, em Kasparov e em mim. Assim, aqueles que pensam que as máquinas programadoras prometidas pela singularidade seriam transhumanas, pressupõem a possibilidade de uma forma de pensamento alheio à lógica. Mas a lógica ${ }^{3}$ é um limite que nenhum pensamento pode transcender, e este limite diz que a intelecção da realidade se guia por certas regras que permitem processar a informação com a qual se pode apreender ou descobrir a própria estrutura ordenada do real. Assim, o evento da "singularidade" traria a termo, não uma nova inteligência, mas apenas uma inteligência que executa as tarefas intelectuais de maneira mais perfeita e rápida. Se se preferir, pode-se dizer que ela traz a termo uma diferença meramente quantitativa, não qualitativa, em relação à inteligência humana.

Agora, se o golem moderno não nos deixa senão insatisfeitos com a subhumanidade do essencialmente mudo golem moderno, pode-se esperar melhor sina para o homúnculo moderno? Poderiam, por acaso, preencher essa lacuna as

\footnotetext{
${ }^{3}$ O pressuposto que aqui sigo é o de que a lógica é um dos critérios de determinação da inteligência. Não há nenhuma forma de vida que está mais além da lógica. As várias lógicas que encontramos atualmente (p. ex.: lógica paraconsistente etc.), tão defendidas por Günther e Sloterdijk, por exemplo, são variações da lógica em geral, pois a pluralidade das lógicas enquanto instrumentos de ação precisa fundar-se na lógica enquanto tal.
} 
novas perspectivas trazidas pela engenharia genética? A primeira coisa a se dizer a esse respeito é que para não falar da terapia genética ou somática que deixou de lado, em 1994, o posto de promessa para se tornar realidade, a manipulação genética germinativa é já mais do que uma promessa, um quase-fato, para os humanos, se se considera os estrondosos resultados que se tem conseguido para o resto da escala vital. Para deixar de lado ratos, coelhos e gatos, basta-nos lembrar que, em 2001, Gerald Schatten criou o primeiro primata transgênico, ANDi, um macaco Rhesus que recebeu um gene que quando expressado faz com que o macaco brilhe no escuro (cf. STOCK, 2003, p. 50).

É aqui que a pergunta sobre a possibilidade da manipulação genética levada a cabo com o auxílio da técnica de DNA recombinante, por exemplo, deve ser feita: pode-se dizer que um indivíduo da espécie humana manipulado no mesmo sentido de ANDi poderia ser considerado como outra coisa que não um humano? Seria esse ente, que passou por tal processo de manipulação genética, um ente transhumano? Naturalmente, só um ponto de vista substancialista muito ingênuo mais uma vez pode considerar as coisas nesses termos. Foi tendo em vista isso que em seu ensaio intitulado "Can anyone really be talking about ethically modifying human nature?" (2009), Daniels parece questionar a seriedade da pergunta feita. Primeiro ele analisa o que seria possível dizer sobre a alteração da natureza de uma mosca da fruta, e aplica o mesmo tipo de análise aos seres humanos. Isso, ele o faz para mostrar que o conceito de natureza humana é populacional, disposicional e seletivo. Quer isto dizer: o que, para ele, define a natureza humana é a "delimitação de certos traços específicos (fator seletivo) de uma dada população (fator populacional), desde que se entenda que os traços que caracterizam tal natureza humana são aqueles em que as pessoas possuem a disposição para exibi-los sob condições [ambientais] específicas, mas nem sempre” (DANIELS, 2009, p. 32), ou em outros termos, traços que não são necessariamente universais, mas que podem aparecer segundo certas circunstâncias (fator disposicional). Daniels oferece alguns casos para exemplificar sua posição, e com isso ele acrescenta ainda algumas informações importantes. Se se altera, por exemplo, uma população no sentido de deixar todos 
os seus membros mais altos ou mais protegidos contra morbidez, isto não altera a natureza humana, já que tais características não definem tal natureza (isto é, falta a tal alteração afetar um traço seletivo). Coisa diferente parece ocorrer, segundo Daniels, quando se altera traços próprios da emotividade (emotionality). Seguindo essa linha, que considera que "não ter qualquer tipo de resposta emocional está além inclusive da patologia humana (com exceção de estado vegetativo persistente)" (DANIELS, 2009, p. 35), se a utilização de uma droga - e note-se que aqui ele não exige sequer manipulação genética) transforma as pessoas em zumbis ou as deixa tímidas, e se esse efeito é permanente e atinge toda a população, então modifica a natureza humana, embora ainda não se trate aí de uma modificação grande da sociedade e da cultura. Na mesma direção, o autor afirma que mesmo novas capacidades não são o suficiente para alterar a natureza de um ser vivo. Ele dá o exemplo de um porco modificado para produzir proteínas humanas: neste caso ainda teríamos um porco e não outra coisa. O mesmo se pode dizer de oferecer novas capacidades aos humanos, como aquela de pular sobre casas, ou de percepção extra-sensorial. Tudo isso seria diferente, entretanto, se o poder conferido fosse aquele de poder ler mentes: segundo Daniel, isso alteraria completamente as relações sociais, a vida privada não existiria e a política mudaria completamente. De qualquer forma, a modificação teria que alcançar a esfera populacional. Todas essas intricadas condições para a determinação de uma alteração da natureza humana dão os motivos para Daniels ironicamente "deixar a ética da ficção científica para outros" (DANIELS, 2009, p. 42).

Não obstante esse ceticismo de Daniels, em seu "Humanity's End” (2010) Nicolas Agar apresenta uma forma mais sagaz de pensar o problema. O autor parte também como Daniels de um conceito biológico de espécie, e pensa os seres humanos como membros da espécie Homo sapiens. E ele adota o conceito biológico de espécie apenas para determinar a existência da espécie no interior da qual certos valores são apreciados e nesse sentido merecem ser preservados. Com tal conceito como orientação, Agar então tenta mostrar que as duas formas do que ele chama "melhoramento radical" (radical enhancement) atuam de modo a tanto melhorar 
(quantitativamente) os poderes cognitivos como também prolongar substancialmente a vida dos indivíduos. Embora tais alterações não sejam em si mesmas a marca de um transhumano, tais formas de "melhoramento radical" podem causar diferenças e consequentemente barreiras reprodutivas. Ele explica isso sugerindo que pessoas superinteligentes não tratarão os menos privilegiados intelectualmente como possíveis parceiros sexuais, do mesmo modo que os futuros virtualmente "imortais" (uma vida que dura mais de mil anos) dificilmente se prestarão a um envolvimento amoroso com um indivíduo que morre na mais tenra idade de 90 a 100 anos. São barreiras reprodutivas desse tipo as candidatas à determinação da separação biológica de duas diferentes espécies, levando assim a uma nova forma de evolução biológica. Se bem se observa, o que Agar faz é apenas a aplicação do conceito biológico de especiação para delimitar uma possível separação biológica entre indivíduos não manipulados geneticamente e indivíduos radicalmente manipulados geneticamente.

O que se pode dizer dessas considerações acerca da possibilidade biotecnológica de emergência do transhumano? Ela realmente oferece uma via para o transhumano? Quero, por fim, analisar justamente esses aspectos ontológicos pressupostos a passos contados. Será preciso, pois, responder a duas perguntas principais: (1) o que é melhoramento humano? Ou mais precisamente: o que significa dizer que um melhoramento pode dar origem a uma forma de ser transhumana? E (2) o que é o humano para que possa ser ultrapassado?

Sobre a primeira pergunta, há que se notar que enhancement humano pode ser entendido em duas direções distintas. Antes de tudo, como melhoramento de capacidades físicas e mentais humanas. Neste caso, a ideia de um transhumano não aparece, e nada de problemático do ponto de vista ontológico se levanta. Deixo de lado as questões éticas que certamente possam persistir. Mas em um segundo sentido, eis como Vaccari, por exemplo, concebe como

um dos tropos centrais do transumanismo: a noção de superação (transcendendo, ser liberado de, deixar para trás) as limitações biológicas, as restrições do corpo e a constituição naturalmente dada. Os seres humanos são capazes de determinar novos valores para si mesmos que vão além do que é estabelecido por prerrogativas biológicas. No pior dos 
casos, o transhumanismo mais extremo proclama um humanismo heróico no qual a natureza humana é definida por um poder auto-formativo (VACCARI, 2013, p. 47) ${ }^{4}$.

Por mais que se deva elogiar tal tentativa de definição do movimento transhumanista, penso que, apesar de correta em linhas gerais, ela falha em um ponto central: o transhumanismo não é um tipo de humanismo. Embora certamente não seja um anti-humanismo, isto é, embora não se trate de se posicionar contra os humanos singulares propriamente, trata-se sem sombra de dúvidas de um rebelar-se contra a natureza humana enquanto tal, vista como deficiente e melhorável. Isto fica particularmente com os casos salientados acima, como os borganismos, as máquinas programadoras supostamente trans-lógicas, os poderes de ler mentes etc. E é explicitamente dito por Buchanan (2009, p. 141, grifo meu): "não há nada de errado, por si só, em alterar ou destruir a natureza humana, porque, em uma compreensão plausível do que é a natureza humana, ela contém características ruins e boas". Penso por isso que o transhumanismo é um movimento intelectual que pretende melhorar a espécie humana valendo-se do recurso da nova tecnologia para a formação de um ente propriamente transhumano. E é por isso que a pergunta pelo ser humano precisa ser elucidada antes que se ofereça a resposta sobre a possibilidade de um ser transhumano.

E como as considerações de Daniels e Agar que revisitamos acima sugerem a emergência do transhumano? Como o resultado de uma evolução biotecnologicamente orientada da espécie biológica Homo sapiens. A respeito desta resposta, o que precisa ser salientado aqui é que tal como a cibernética e seus intentos de fabricação de inteligências artificiais transhumanas têm em seu fundo a

\footnotetext{
4 “Existem fortes continuidades entre o mecanicismo biológico clássico e a antropologia transumanista. Ambos instrumentalizam a relação entre corpo e mente, desdobrando o humano em sujeito e objeto de sua ação, em designer e design. O processo de elevação moral humana, tanto para Descartes quanto para os transumanistas, passa pela correção de sua condição biomaterial. Descartes inscreve este projeto de melhoria física no âmbito da medicina clássica e seus propósitos explicitamente morais. A ciência é um instrumento de moralidade e, portanto, a moralidade deve ser o nosso guia no processo de autoconhecimento e auto-aperfeiçoamento" (VACCARI, 2013, p. 50).
} 
metafísica própria da era da informação, também os proponentes da evolução biotecnológica têm como pressuposto metafísico o biologismo cientificista, que se soma a certa desconsideração aos mais audazes desenvolvimentos da ontologia contemporânea.

A ingenuidade de um naturalismo biologizante pode dar a entender que a diferença entre o humano e o não humano é meramente de grau. Neste caso, ser humano pode significar, por exemplo, ser quantitativamente mais inteligente, possuir um vocabulário linguístico exorbitantemente maior do que outros animais superiores. Mas esse tipo de redução antropológica é insuficiente. E apesar da diferença com essa primeira maneira de determinar a diferença antropológica, o reducionismo é ainda o caso com o que nos oferecem Daniels e Agar. A ideia de natureza humana aí está estreitamente atrelada a um conceito biológico de espécie. Por mais que seja superior à posição anterior, que busca a diferença antropológica numa medida, as posições de Daniels e Agar têm a vantagem de buscar a diferença antropológica numa diferença comportamental, que enquanto tal é pensada desde um ponto de vista populacional, isto é, a partir de vários indivíduos, e atendem ainda ao fator disposicional de que fala Daniels. Ora, mas se bem se percebe esse conceito de natureza humana defendido por Daniels, especialmente lembra muito o conceito nomológico de Edouard Machery (2008). Em seu artigo "A plea for human nature” (2008), Machery busca refutar a posição de filósofos da biologia como David Hull (1987) e Michael Ghiselin (1997), para os quais o conceito de natureza humana é incompatível com a moderna biologia evolutiva. Para Machery, há compatibilidade, eis sua tese central. Antes dele e também depois dele, psicólogos, linguistas, e cientistas cognitivos usaram e continuam a usar abundantemente a noção de natureza humana e argumentam em seu favor (cf. CHOMSKY, 1971; WILSON, 1979; TOOBY; COSMIDES, 1990; PINKER, 2003).

Em contraposição à noção essencialista segundo a qual "a humana natureza humana é o conjunto de propriedades [tipicamente pensadas como distintivas dos humanos] que são separadamente necessárias e conjuntamente suficientes para ser 
um humano" (MACHERY, 2008, p. 322), o que essa concepção nomológica apresentada por Machery defende é o seguinte:

a natureza humana é o conjunto de propriedades que os humanos tendem a possuir como resultado da evolução de sua espécie. De acordo com essa noção, ser bipedal é parte da natureza humana, porque a maioria dos seres humanos são animais bípedes e porque o bipedismo é um resultado da evolução dos seres humanos. O mesmo se aplica ao investimento biparental em crianças, medo de reações a ruídos inesperados ou a capacidade de falar (MACHERY, 2008, p. 323).

Segundo Machery, essa noção inverte a relação aristotélica entre natureza e generalização, pois enquanto para Aristóteles as generalizações podem ser feitas porque os homens possuem uma mesma natureza, para Machery é o fato de generalizações poderem ser feitas sobre os humanos, explicando a existência de uma natureza humana. A diferença mais importante com a noção essencialista se deve ao fato de que "as propriedades que são parte da natureza humana não são nem necessária nem conjuntamente suficientes para ser humano" (MACHERY, 2008, p. 323). Assim, uma vez que as propriedades não são definicionais, elas não precisam aparecer em todos os seres humanos. Nem todos os humanos precisam falar (uma vez que depende de exposição à linguagem) ou ter reações de medo (depende de bom funcionamento da amídala). A definição só exige, portanto, que as propriedades humanas sejam compartilhadas apenas pela maioria dos indivíduos da espécie enquanto parte do processo evolutivo. Tais propriedades não precisam ser possuídas apenas por humanos. Ademais, tal natureza não é permanente, mas antes pode mudar.

Mas, como mostrou Richard Samuels (2012), apesar de muitas disciplinas como anatomia, fisiologia, neurociência e ciências comportamentais e cognitivas, conseguirem estabelecer regularidades típicas à espécie, fato é que a definição nomológica não parece atender a todos os requisitos da definição essencialista tradicional de natureza humana. Embora a concepção nomológica desempenhe os papéis organizacional e descritivo da concepção tradicional, ela falha na função taxonômica, por pelo menos dois motivos: (1) é duvidoso que segundo a concepção nomológica ter uma natureza humana signifique o mesmo que ser humano, isto é, 
"é duvidoso que todos e apenas reais humanos satisfaçam o espectro relevante de regularidades" (SAMUELS, 2012, p. 17). Como exemplos, termos os afásicos, os agnósicos visuais e auditivos e os amenésicos, os quais respectivamente não atendem a regularidades concernentes à linguagem, percepção e memória. Além disso, (2) Samuels afirma que se poderia ser humano sem possuir uma natureza nomológica, já que "os seres humanos poderiam evoluir de tal forma que muitas das generalizações existentes não mais se sustentassem” (SAMUELS, 2012, p. 17).

A concepção nomológica ainda falha também quanto ao papel causalexplictivo da concepção tradicional. Ora, a natureza humana é vista como um fator causal subjacente para o aparecimento das regularidades envolvendo seres humanos. Mas se a natureza humana é apenas o conjunto de regularidades típicas ao humano, então ela não pode ser a causa dessas regularidades. É certo que o conceito nomológico pode realizar algum papel explicativo, mas ele não permite pensar que a natureza é uma estrutura subjacente que oferece o papel central de explicação das propriedades mais superficiais de um ente (cf. SAMUELS, 2012, p. 18).

Por isso, como alternativa à concepção de Machery, Richard Samuels, com sua versão de um essencialismo causal da natureza humana, afirma que "as essências são entidades - mecanismos, processos e estruturas - que causam muitas das propriedades e regularidades mais superficiais confiavelmente associadas com um gênero” (SAMUELS, 2012, p. 20). Mais:

\begin{abstract}
da maneira que uso os termos, todas as essências taxonômicas são essências causais, mas não o contrário. Pois além de figurar em explicações causais, uma essência taxonômica é, por uma questão de necessidade metafísica, possuída por todos os membros de um gênero e apenas por eles. Em contraste, as essências causais não precisam sequer ser possuídas por todos os membros do gênero, muito menos serem individualizadas desse tipo. Eles podem, por exemplo, estar faltando em membros desviantes, anormais ou limítrofes do tipo (SAMUELS, 2012, p. 20n31).
\end{abstract}

Essa concepção do essencialismo causal acomoda as funções organizacional, descritiva, de especificação de fixidez, causal-explicativa. Portanto, ela oferece a manutenção de mais funções da concepção tradicional do que a concepção nomológica (que acomoda apenas as três primeiras funções citadas). O que ela não 
acomoda da concepção tradicional, entretanto, é sua função taxonômica. Mas, segundo ele, os fatos biológicos não permitem mais essa acomodação.

Existem uma série de outras concepções que não abordarei, mas podem ser encontradas no ensaio de Maria Kronfeldner, Neil Roughley e Georg Toepfer (2014). Aqui me permito partir para as minhas considerações críticas em relação ao que estas novas concepções da natureza humana sugerem para a discussão da emergência biotecnológica do transhumano, no sentido de Daniels e Agar.

A pergunta que logo se deve fazer é: aquilo que os filósofos já há muito pensam com o termo natureza humana se confunde com uma espécie natural? A essência humana se identifica com alguma espécie natural com determinados níveis de memória e atenção, por exemplo, ou é de outro modo? Podemos creditar o surgimento do transhumano simplesmente ao isolamento geográfico e reprodutivo de indivíduos com capacidades quantitativamente diferenciadas? A posição de Agar especialmente parece sugerir isso. E como acabamos de ver, ela destoa das novas investidas que alguns filósofos têm realizado em relação ao conceito de natureza humana. Mesmo a posição nomológica de Daniels recebeu, como mostrei, diversas correções, que em boa medida podem inclusive dar base a concepções não biologizantes da essência humana, tal como oferecida pelos filósofos desde há muito. Mesmo alguns transhumanistas cibernéticos, como Kurzweil por exemplo, sabem bem que uma existência inteligente pode ser transbiológica. Este simples fato já descarta a necessidade de se atender às restrições impostas pelos biólogos para a discussão acerca da natureza humana. Nesse sentido, eles concordam com Kant quando este, contra Herder, afirma que a organização que permite a criatura humana ter uma razão não é algo necessário, mas contingente (KANT, 1968, p. 57), ou seja, a razão humana - para Kant, a faculdade distintiva do humano - pode se dar numa forma de organização diferente da forma atual.

É preciso, pois, entender que a discussão sobre a natureza humana é de uma complexidade que merece maior atenção. E todo o problema se agrava se entendermos que há ainda diversas concepções de natureza humana, e é difícil estabelecer qual delas possui o direito ao posto de primeiro lugar. Não obstante, se 
se leva a sério o que, em última instância, uma definição contemporânea forte, não substancialista, da essência humana tem a dizer, pode-se notar que ela não pode fugir muito ao fato de que o homem é aquele ente que vive segundo a imagem que ele constrói de si mesmo segundo o limite de sua inteligência. Há certamente muita controvérsia em relação ao que permite e determina esse modo de ser, se a razão, se a liberdade, ou as duas ao mesmo tempo ou ainda algo diferente, mas não parece que a definição em si seja tão controversa.

E com essa definição em mãos podemos retornar ao nosso problema. As diversas formas de antropotécnica discutidas, sejam elas cibernéticas ou biotecnológicas, permitem alterar a natureza humana no sentido ora analisado? Vistas desde essa compreensão da natureza humana, elas realmente oferecem uma via para a emergência do transhumano? Como tentei demonstrar, o caso da cibernética não oferece tal possibilidade, porque mesmo que o cenário da chamada "singularidade" se torne realidade, permitindo que computação transbiológica ultrapasse a capacidade humana, não se está autorizado a concluir a partir disso que o surgimento do transhumano, pois o pensamento humano não é uma capacidade computacional ou calculativa, mas sim uma capacidade de pensar a realidade que é ordenada segundo os limites da lógica interna ao pensar mesmo, limites aos quais a capacidade computacional das máquinas também precisa atender. O caso da bioengenharia é mais complexo. É certo que os cenários pintados por Daniels e Agar especificamente são pouco sustentáveis, porque não respondem ao que de fato pode ser considerado natureza humana. Mas elas permitem vislumbrar em que sentido a bioengenharia pode levar a uma desfiguração da natureza humana ao limitar o poder auto-formativo do homem em construir uma imagem de si mesmo, já que seus resultados são irreversíveis, selecionando de uma vez por todas os traços típicos da espécie humana na terra, o que, por sua vez, impede que as gerações futuras de humanos possam ter à sua disposição certas possibilidades que estavam abertas para seus progenitores. Assim, o problema que a biotecnologia levanta não é propriamente a emergência de uma nova forma de inteligência com padrões lógicos diferentes e melhores, mas uma diminuição do horizonte de abertura do agir 
humano ${ }^{5}$. Desse modo, embora seja certo que, desde um ponto de vista meramente quantitativo, muitas capacidades humanas possam ser ampliadas com o recurso das biotecnologias, bem como também traços não tipicamente humanos $\mathrm{e}$ aparentemente desfavoráveis (p. ex. a mortalidade) possam ser revertidos, o fato é que isto só ocorreria, desde a perspectiva do gênero humano, em detrimento de um horizonte de abertura maior para o ser humano, portanto em prejuízo para o gênero humano. $\mathrm{O}$ resultado desde a perspectiva do gênero humano - não necessariamente desde a perspectiva de um único indivíduo humano — seria que a antropotécnica biotecnológica em algumas de suas intervenções não levaria a uma evolução e progresso do homem, à emergência do transhumano, mas antes a uma involução e retrocesso do homem, que veria o livre horizonte de sua existência reduzido a traços característicos epocalmente determinados como absolutamente superiores, o que seria o mesmo que dizer que uma antropologia epocal, isto é, a imagem que uma dada época faz do que seria o melhor para o homem, adquiriria o status de uma antropologia quase-absoluta.

Para encerrar este ensaio, gostaria de observar, entretanto, que embora o esclarecimento das questões ontológicas envolvidas em tal controvérsia permita concluir que o transhumano permanece ainda um sonho utópico tanto quanto o eram o golem e o homúnculo da tradição alquímica, ele não elimina necessariamente outras questões de ordem ética e política, as quais precisam certamente de um estudo complementar.

\section{Referências}

AGAR, N. Humanity's End: Why We Should Reject Radical Enhancement. Cambridge: MIT Press, 2010.

ARISTÓTELES. Física. Editorial Gredos, S.A., 1995.

\footnotetext{
${ }^{5}$ Em outro texto, mostrei que para Hans Jonas a manipulação genética do homem deve ser evitada, seja em suas metas meramente utilitaristas ou mesmo em sua meta supostamente melhorista, exatamente porque gera um prejuízo definitivo à liberdade à liberdade humana, tanto em seu sentido existencial quanto político (cf. LOPES, 2018).
} 
BUCHANAN, A. Human Nature and Enhancement. Bioethics, v. 23, n. 3, p. 141-150, 2009.

CHOMSKY, N. Human Nature: Justice vs. Power. In: CHOMSKY, N.; FOUCAULT, M. The Chomsky-Foucault Debate On Human Nature. New York: New Press, 1971. p. 1-67.

HULL, D. On human nature. PSA: Proceedings of the Biennial Meeting of the Philosophy of Science Association, v. 1986, Volume Two: Symposia and Invited Papers, p. 3-13, 1986.

DANIELS, N. Can Anyone Really Be Talking about Ethically Modifying Human Nature? In: SAVULESCU, J.; BOSTROM, N. Human Enhancement. Oxford: Oxford University Press, 2009. p. 25-42.

FEENBERG, A. Introduction: toward a Critical Theory of the Internet. In: FEENBERG, A.; FRIESEN, N. (Re)Inventing the Internet. Rotterdam: Sense Publishers, 2012. p. 3-17.

GHISELIN, M. T. Metaphysics and the origins of species. Albany: State University of New York Press, 1997.

GÜNTHER, G. Das Bewußtsein der Maschinen. Eine Metaphysik der Kybernetik. Krefeld und Baden-Baden: Agis-Verlag, 1963. (I ed. 1957. p. 167-173, Appendice I).

JONAS, H. Maschinen werden niemals ein Bewußtsein haben können. In: SCHNEIDER, W. (Hrsg.). Dem bösen Ende näher: Gespräche über das Verhältnis des Menschen zur Natur. Frankfurt am Main: Suhrkamp, 1993. p. 49-52.

KANT, I. Kants Werke: Akademie-Textausgabe B. VIII: Abhandlungen nach 1781. Berlin: Walter de Gruyter \& Co., 1968.

KRONFELDNER, M. ROUGHLEY, N.; TOEPFER, G. Recent Work on Human Nature: Beyond Traditional Essences. Philosophy Compass, v. 9, n. 9, p. 642-652, 2014.

KURZWEIL, R. The Singularity is Near: When Humans Transcend Biology. New York: Viking, 2005.

LOPES, W. E. S. A crítica de Hans Jonas ao enhancement humano. Dissertatio, v. Suplementar, n. 7, p. 70-92, 2018.

MACHERY, E. A plea for human nature. Philosophical Psychology, v. 21, n. 3, p. 321-329, 2008.

NEWMAN, W. R. Promethean Ambitions. Chicago: The University of Chicago Press, 2004.

PINKER, S. The Blank Slate: The Modern Denial of Human Nature. London: Penguin Press Science, 2003.

SAVULESCU, J. Procreative Beneficence: Why We Should Select the Best Children. Bioethics, v. 15, n. 5-6, p. 413-426, 2001.

SAVULESCU, J.; BOSTROM, N. Introduction. In: Human Enhancement. Oxford: Oxford University Press, 2009. p. 25-42. 
SEARLE, J. Is the brain's mind a computer program? Scientific American, p. 26-37, Jan. 1990.

SAMUELS, R. Science and Human nature. Royal Institute of Philosophy Supplement, n. 70, p. 124, 2012.

SLOTERDIJK, P. A Natureza por Fazer. O Tema Decisivo da Época Moderna. In: AGAMBEN, G.; MARRAMAO, G.; RANCIÈRE, J.; SLOTERDIJK, P. Porto: Fundação de Serralves, 2008. p. 103-128.

SLOTERDIJK, P. Sin Salvación: tras las huellas de Heidegger [2001]. Madrid: Ediciones AKAL, 2011.

SLOTERDIJK, P. Has de cambiar tu vida: sobre antropotécnica. Trad. de Pedro Madrigal. Valencia: Pre-Textos, 2012.

STOCK, G. Redesigning Humans: our inevitable genetic future. New York: Houghton Mifflin Company, 2002.

TOOBY, J.; COSMIDES, L. On the universality of human nature and the uniqueness of the individual: The role of genetics and adaptation. Journal of Personality, n. 58, p. 17-67, 1990.

VACCARI, A. La idea más peligrosa del mundo: hacia una crítica de la antropología transhumanista. Tecnología \& Sociedad, Buenos Aires, v. 1, n. 2, p. 39-59, 2013.

WILSON, E. O. On Human Nature. Cambridge: Harvard University Press, 1979.

RECEBIDO: $16 / 01 / 2020$

APROVADO: $25 / 02 / 2020$

RECEIVED: 01/06/2020

APPROVED: 02/25/2020 